\title{
Citizen science on a smartphone: Participants' motivations and learning
}

Public Understanding of Science 2016, Vol. 25(I) 45-60

(C) The Author(s) 2015

Reprints and permissions: sagepub.co.uk/journalsPermissions.nav DOI: $10.1177 / 0963662515602406$ pus.sagepub.com

\section{Anne M. Land-Zandstra}

Leiden University, The Netherlands

\section{Jeroen L. A. Devilee}

National Institute for Public Health and the Environment (RIVM), The Netherlands

\section{Frans Snik}

Leiden University, The Netherlands

\section{Franka Buurmeijer}

Dutch Research School for Astronomy (NOVA), The Netherlands

\section{Jos M. van den Broek}

Leiden University, The Netherlands

\begin{abstract}
Citizen science provides researchers means to gather or analyse large datasets. At the same time, citizen science projects offer an opportunity for non-scientists to be part of and learn from the scientific process. In the Dutch iSPEX project, a large number of citizens turned their smartphones into actual measurement devices to measure aerosols. This study examined participants' motivation and perceived learning impacts of this unique project. Most respondents joined iSPEX because they wanted to contribute to the scientific goals of the project or because they were interested in the project topics (health and environmental impact of aerosols). In terms of learning impact, respondents reported a gain in knowledge about citizen science and the topics of the project. However, many respondents had an incomplete understanding of the science behind the project, possibly caused by the complexity of the measurements.
\end{abstract}

\section{Keywords}

acquisition of new technologies, health and new technologies, public participation

\section{Corresponding author:}

Anne M. Land-Zandstra, Department of Science Communication \& Society, Leiden University, P.O. Box 9505, 2300 RA Leiden, The Netherlands.

Email: a.m.land@biology.leidenuniv.nl 


\section{Introduction}

The term 'citizen science' (CS) commonly refers to the involvement of the general public in different stages of the scientific process, often during data collection or analysis (Bonney et al., 2009a; Science Communication Unit, University of the West of England-Bristol, 2013). Although popularity of CS has increased recently, it is not necessarily a new practice. A well-known example of CS is the Audubon Society's Christmas Bird Count, which has been running in the United States every year since 1900. In Europe, similar projects have been recruiting the general public for years to gather data about the presence of birds, butterflies or invasive species (e.g. Open Air Laboratories, United Kingdom; ${ }^{1}$ nature calendar, The Netherlands ${ }^{2}$ ). Currently, many different types of CS projects exist, ranging from volunteers measuring water quality to online communities of people analysing pictures of galaxies (Galaxy Zoo; Raddick et al., 2010; for overview of different projects, see Wiggins and Crowston, 2012).

Citizen scientists can get involved in different stages of the scientific process: development of hypotheses, methodology design, data collection, data analysis and dissemination of data. Several frameworks have been developed to classify the different types of CS projects according to the steps in the scientific process to which citizens contribute (Bonney et al., 2009a; Haklay, 2012; Roy et al., 2012). Here, we use the classification system of Bonney et al. (2009a). This framework consists of three models for public participation in scientific research. They define contributory projects as projects that are designed by scientists; the public is mainly involved in collecting or analysing data. Most of the current CS projects can be categorised as contributory projects (Roy et al., 2012). Citizen scientists make it possible to gather data in large volumes and over large geographical areas or to analyse large amounts of data by dividing up the work over many participants (Riesch et al., 2013; Silvertown, 2009).

In collaborative projects, researchers still develop the research questions and the overall study design. However, participants have larger influence on the scientific process. For example, they help with interpreting the data and drawing conclusions, or they help to adjust protocols for data collection or propose new directions for the study. Last, co-created projects are developed in full collaboration between the public and scientists. Often, members of the public come up with relevant research questions and work with scientists during all stages of the study.

The goals for CS projects are generally twofold: scientific output and science outreach (Bonney et al., 2009a). In the last decades, the number of scientific articles based on CS data in peerreviewed journals has increased substantially, indicating that citizen scientists are contributing to research (Catlin-Groves, 2012). Simultaneously, CS is recognised as a way for the public to get in touch with and learn about science (Bonney et al., 2009b). CS projects seem to be a way for the public to learn not only about scientific facts but also about the process of science (Brossard et al., 2005; Cronje et al., 2011; Jordan et al., 2011).

Recently, the practice of CS has grown substantially. One of the reasons for this growth is the increasing availability of technologies such as the Internet, handheld computers (personal digital assistant (PDA)) and smartphones that make it easier for scientists and citizens to connect with each other and to gather and analyse data (Reed et al., 2013; Silvertown, 2009). Some CS projects, such as Galaxy Zoo (as part of the larger project Zooniverse ${ }^{3}$ ), take place entirely online and have become known as virtual CS (Jennett et al., 2014).

In addition, smartphones are used increasingly as a means to record observations and send them to a central project database (Newman et al., 2012). Camera and global positioning system (GPS) applications on smartphones allow citizen scientists to send pictures and other data tagged with geospatial information. However, most of these projects use smartphones as record keeping or communication devices. Only few CS projects turn smartphones into actual measurement devices. 
For example, Project NoiseTube ${ }^{4}$ uses the microphone on smartphones to monitor noise pollution. The iBats program ${ }^{5}$ connects a smartphone to a bat detector to record ultrasonic bat sounds and monitor bat populations. The iSPEX project, which is the focus of this study, is another example of a CS project that turns smartphones into measurement devices (see detailed description below).

\section{Motivation to participate}

Within the growing field of CS, it is important to understand why people get involved in these projects in order to attract and maintain a pool of citizen scientists. Different categories of motivators have been determined (Evans et al., 2005; Nov et al., 2011b; Raddick et al., 2013; Socientize, 2013). Some participants become involved because they want to contribute to scientific research or to the environment. Others are motivated by an interest in the scientific topic, in the specific project or in science in general. Other reasons to participate are because volunteers find the CS activities enjoyable or fun. Another reason may be because they like the opportunity to get involved with other people with similar interests, either tangibly or virtually through blogs and forums (Chu et al., 2012; Dickinson et al., 2012; Lee and Roth, 2003; Rotman et al., 2012; Wymer, 2003).

Generally, motivational factors are important at two different points in time for CS projects: the initial motivation to participate and the motivation to stay involved (Mueller et al., 2012; Rotman et al., 2012). Rotman et al. (2012) developed a process model of involvement in CS based on the motivational framework of Batson et al. (2002). Batson et al. (2002) identify four categories of motives for community involvement in general: egoism, altruism, collectivism and principlism. Egoism relates to motives that pertain to one's own welfare. Altruistic motives are related to increasing the welfare of others. Collectivism refers to increasing the welfare of a group. Principlism includes motives related to upholding a moral principle (e.g. justice, equality, caring for the environment). Rotman et al. (2012) found that egoism was the most important motivational category at the initial stages of participation, where during continued participation collectivism and altruism play a more important role. They propose that responding to the different motivational factors at different points of participation will help keep participants engaged. Since many citizen scientists, especially in the field of virtual CS, participate only for a short period of time and only a small portion of citizen scientists stick with a certain project (Nov et al., 2011a; Riesch and Potter, 2014; Sauermann and Franzoni, 2015; Theobald et al., 2015), it is important to study the motives of citizen scientists.

\section{Learning impact}

As one of the reasons for scientists to organise CS projects is to inform the public about scientific topics, it is also important to determine what participants learn from these projects. CS seems a promising way to teach people about different scientific topics as well as the scientific process (Bonney et al., 2009a; Brossard et al., 2005; Evans et al., 2005; National Research Council, 2009; Trumbull et al., 2000). In a review of several projects for public participation in scientific research, Bonney et al. (2009a) concluded that most projects showed signs of an impact on scientific knowledge, ranging from project-specific knowledge about bird species to an increased understanding of the scientific process. However, not all projects seem to be equally effective in increasing the understanding of science content and the scientific process (Crall et al., 2012; Druschke and Seltzer, 2012). Crall et al. (2012) suggest that one reason for this lack of impact is that the design of many CS projects does not explicitly make participants aware of how the protocols for data collection or analysis relate to the practice of real science. Evans et al. (2005) found that the increase in science knowledge was impacted by the interaction between scientific staff and participants. In 
addition, many citizen scientists participate in these projects to learn more about the scientific topic under study, rather than to learn more about the scientific process (Brossard et al., 2005; Cronje et al., 2011; Jordan et al., 2011). Information about what and when people learn from CS projects may help develop projects that have an impact on citizen scientists' science knowledge. In this study, we looked at motivational factors as well as self-reported learning impact of one particular CS project, iSPEX. ${ }^{6}$

\section{iSPEX}

The Dutch iSPEX project ${ }^{7}$ uses an innovative way to measure properties of aerosols, small airborne particles in the atmosphere such as dust, soot or sea salt. Measurement of the properties of aerosols, such as density and chemical composition, is important for health and environmental reasons. The smallest particles can cause health problems when they penetrate lung tissue. In addition, the effect of dust and aerosols on climate change is largely unknown. In the iSPEX project, the properties of aerosols are measured using smartphones with a small add-on in front of the camera (see Figure 1). Together with a dedicated iSPEX app, smartphones measure the spectrum and polarisation of scattered sunlight at their location, which carries information about the aerosol particles that scatter sunlight. The clarity of the sky is a measure for the amount of aerosols in the atmosphere in the complete atmospheric column, not just at ground level. For each measurement, several pictures are sent to a central database where all data are analysed and combined into a map of aerosol parameters (density, size, chemical composition). Taking an average of several measurements is necessary to obtain sufficient accuracy, as the accuracy of a single measurement is low. The iSPEX measurements add new information about aerosols to the information gathered through established monitoring networks and satellite observations (Snik et al., 2014).

In terms of the classification system described above (Bonney et al., 2009a), iSPEX can be classified as a contributory CS project. Researchers have designed the project and developed the data collection protocol. Citizen scientists take active measurements in the data collection stage of the study. Participants were recruited through different media (including newspapers, television, science magazines and through partner organisations) and were kept informed through regular email newsletters.

In order to try to help participants understand the project, its purpose and the science involved, the iSPEX team used their website, regular newsletters and the different media mentioned above. The project website contained information about the scientific topics relevant to the project, the technology behind the measurements, CS, the reasons for this type of research and instructions for the measurements. The iSPEX team was available through email for questions about the app and about the project in general.

In 2013, two large-scale national measurement campaigns were organised in the Netherlands. On 8 July, the first measurement day, 6007 iSPEX measurements were done (5971 in the Netherlands). On 9 July, 1546 spontaneous measurements were submitted. The second national measurement day, 5 September, resulted in 2416 measurements.

The iSPEX project is a relatively new type of CS, where a large group of participants turn their smartphones into measurement devices and collect and transmit data at the same day. This is fundamentally different from using smartphones only to collect and record observational data. Within these new types of CS, iSPEX distinguishes itself by the two large-scale, nationwide measurement campaigns. Little is known about the participants of such projects, why they participate and what they learn. The aim of the current participant study was (1) to examine the motives and conditions 


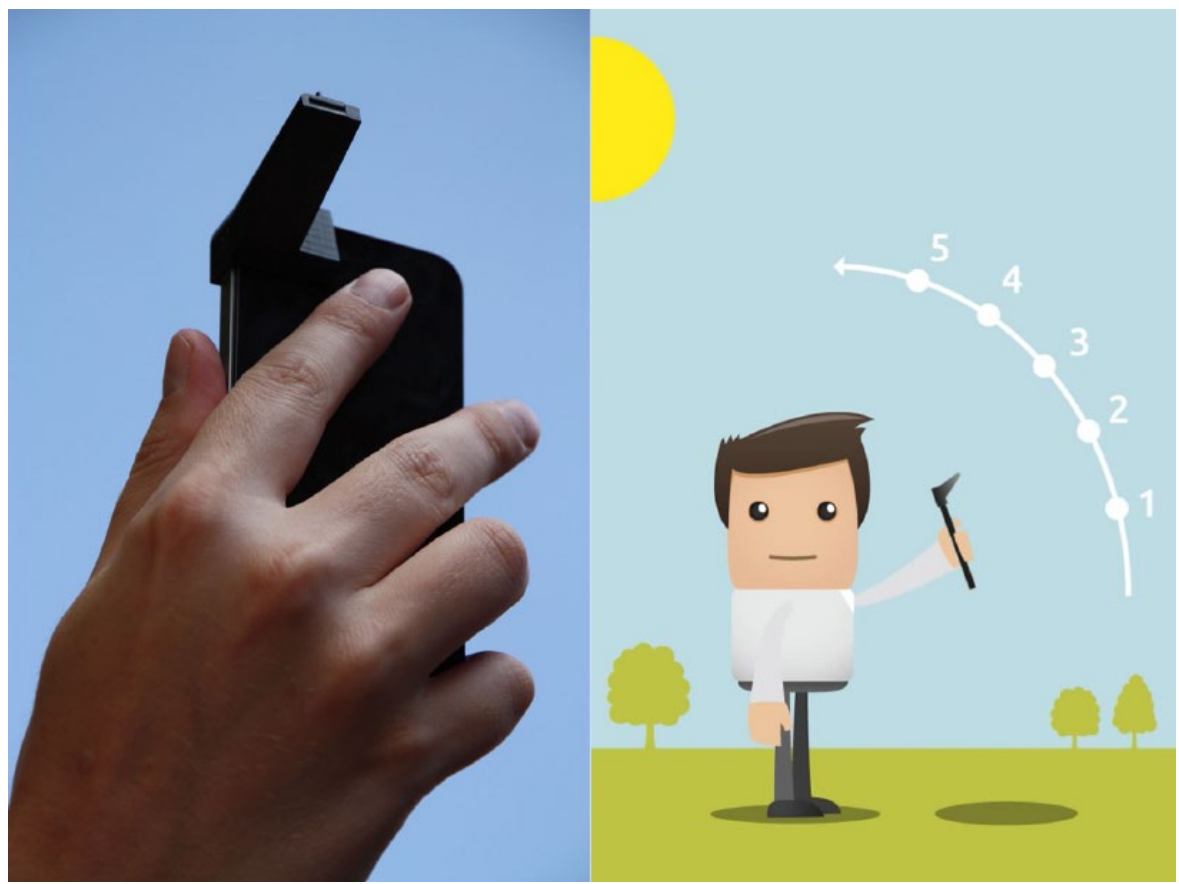

Figure I. The iSPEX add-on on a smartphone on the left, instruction for taking measurements on the right.

of citizens for (continued) participation in the iSPEX project and (2) to examine the impact of participation on citizens' understanding of science in general and aerosols in particular.

\section{Methodology}

\section{Data collection}

In order to answer the research questions, an online survey was conducted. The survey consisted of 42 questions within different categories: experience during the iSPEX project, demographic information, previous experience with scientific research and CS, attitude towards science, selfreported learning impact, motivation for participation, conditions for future participation, expectations about the project and understanding of the project (see Appendix 1 (available at: http://pus. sagepub.com/content/by/supplemental-data) for detailed list of translated questions). Question types were a combination of closed, multiple-choice questions and 5-point Likert scale questions, with answers ranging from 'not at all applicable' (1) to 'totally applicable' (5). The questionnaire was developed by researchers in collaboration with several members of the iSPEX team and partner organisations. For some of the categories (attitude towards science, motivation for participation, learning impact), questions were based on existing questionnaires of earlier studies. For example, the questions about motivation were adapted from the motivational categories found by Raddick et al. (2010) complemented with extra motives relevant to this study. In addition, the questionnaire was pilot tested through phone interviews and a preliminary online version. Reliability data will be reported below in the 'Results' section. 
Some limitations have to be taken into account with regard to this questionnaire. First, many questions rely on self-report data. Respondents may have painted an overly positive picture about themselves in terms of their motivations, the impact on their knowledge, their attitude towards science and their intentions to stay involved in the project. Second, we were not able to collect baseline data about respondents' knowledge and attitudes, which would have made it possible to measure a change in knowledge and attitude as a result of the project.

Through the mailing list of the iSPEX project, all participants of iSPEX who had agreed to receive information about the project received an invitation to participate in this research study. Out of the 3187 unique iSPEX participants, 1258 responded to this request, resulting in a response rate of 39\%. This is a reasonable response rate for web surveys (Cook et al., 2000). Of the 1258 responses to the survey, 135 were discarded due to missing data, resulting in a final sample of 1123 valid responses. The fact that respondents form a self-selected sample may add bias to this study.

\section{Respondents}

The average age of the respondents was 51 years (standard deviation $(S D)=12$, range: $10-87$ years). The majority of the respondents were male (71\%). Most of the respondents had finished a form of higher education (80\%). In terms of employment, $60 \%$ worked 32 hours per week or more, $15 \%$ worked less than 32 hours per week, $15 \%$ were retired, $7 \%$ were unemployed and 3\% were students. The geographical distribution of the respondents of this study over the Netherlands was similar to the distribution of the measurements during the two measurement days.

In terms of previous experience, several respondents had some experience with scientific research as a high school student (34\%), a college student (43\%), a researcher (22\%) or a volunteer - for example, as a test subject or active participant in scientific research (27\%). In contrast, 38\% of the study respondents had no previous experience with scientific research. For $59 \%$ of respondents, iSPEX was their first CS project. Others had previous experience with projects such as national bird counts $(24 \%)$, butterfly counts $(10 \%)$ and distributed computing projects such as SETI@home (18\%). Finally, 32\% of respondents had no previous experience with volunteer work.

\section{Data analysis}

In addition to descriptive analysis of the data, principal component analyses and scale analyses were conducted to determine whether different categories of motivations, learning impact and attitudes could be distinguished. Correlational analyses and chi-square analyses were used to discover differences across demographic groups, such as gender and age groups. Spearman correlational coefficients were calculated since Kolmogorov-Smirnoff tests of normality showed that the assumption of normality was violated. Data were analysed using SPSS version 22.

\section{Results}

\section{Involvement in iSPEX project}

The iSPEX project organised two official measurement days. On these days, $949(84.5 \%)$ and 600 (53.4\%) of the respondents, respectively, submitted measurements (with $43.9 \%$ of the respondents contributing on both measurement days). Overall, $60.4 \%$ of the respondents took measurements on other days than the official measurement days. Most people $(80.3 \%)$ submitted two to five measurements per measurement day. 
Although many other CS projects include a social component with people meeting each other and working together or contacting each other through forums or chat (Chu et al., 2012; Dickinson et al., 2012), most of the iSPEX contributors took measurements by themselves $(86.5 \%)$. In addition, 69.1\% were not active on social media (Facebook and Twitter) with respect to iSPEX. However, the majority $(69 \%)$ of the respondents did explain to passers-by what they were doing while they were taking measurements.

\section{Attitude towards science}

Table 1 shows the average scores on the questions about respondents' attitude towards science, scored on a 5-point Likert scale ranging from 'not at all applicable' (1) to 'totally applicable' (5). After principal component analysis, three scales were defined. The scale science activities consisted of six items about science-related activities in everyday life such as reading science news articles, watching television shows about science and attending science lectures. The scale technological optimism included four statements about science contributing to our health, our lives and the environment. The scale trust in science consisted of two items about the trustworthiness of scientists. The item I donate money to scientific or medical research did not load onto any of the scales. The scales science activities and technological optimism had reasonable reliability ( $\alpha$ values of .71 and .77, respectively). The trust scale had a lower reliability $(\alpha=.51)$.

Results show that iSPEX participants have only limited involvement with science in their daily lives. They read newspaper articles (4.19) and watch television shows about science (3.91), but reading magazines (2.83), attending lectures or events (2.78) and following science news on social media (2.62) were not popular. In addition, respondents agreed that science can have a positive impact on our lives (4.19) and they have confidence in the reliability of scientists (3.62).

\section{Motivation for participation}

To determine the reasons for their involvement in iSPEX, respondents were asked to score the applicability of several statements. Principal component analysis revealed five scales: contribution, interest in science, concern for health, fun and use in schools. Reliability coefficients for the five scales ranged from .67 to .85 (see Table 2). The scales contribution $(M=4.41, S D=0.66)$ and interest in science $(M=4.11, S D=0.63)$ received the highest average scores (see Table 2).

Respondents also selected the most important reason for their contribution to the iSPEX project. The top three reasons were contribution to scientific research $(27.5 \%)$, contribution to quality of surroundings (11.8\%) and CS is an interesting method (9.9\%). The least important reasons were to learn more about science $(0.2 \%)$, to get a fun gadget $(0.4 \%)$ and to get involved through Internet and social media $(0.4 \%)$.

Significant differences existed between genders with respect to their motivation to join iSPEX. Women scored higher on the concern for health factor $(t(1121)=3.68, p<.001)$, while men scored higher on both interest in science $(t(546.352)=3.68, p<.001$; unequal variance) and fun $(t(1121)=4.41, p<.001)$ as a motivation to join the iSPEX project. In addition, most of the motivation factors correlated significantly with age. Older people scored higher on contribution, interest, concern for health and fun than younger people (see Table 3).

In order to look at differences in motivation among people with different attitudes towards science, correlational analysis was performed on the three attitude scales science activities, technological optimism and trust in science and the five scales for motivation. Table 3 shows the significant correlations. Highest correlations were found between the activities scale and the scales for interest as motivation $\left(r_{s}=.40\right)$ and fun as motivation $\left(r_{s}=.25\right)$ and between the optimism scale and the 
Table I. Attitude towards science of study participants.

\begin{tabular}{|c|c|c|}
\hline Scale and items & Mean (SD) & Reliability $(\alpha)$ \\
\hline Science activities & $3.34(0.82)$ & .71 \\
\hline I read news articles about science & $4.19(0.98)$ & \\
\hline I attend lectures or events about science & $2.78(1.46)$ & \\
\hline I use knowledge about science in my daily life & $3.70(1.23)$ & \\
\hline I watch television shows about science & $3.91(1.06)$ & \\
\hline I read popular science magazines & $2.83(1.44)$ & \\
\hline I follow science news on social media & $2.62(1.47)$ & \\
\hline Technological optimism & $4.19(0.59)$ & .77 \\
\hline Science and technology make our lives healthier & $4.04(0.86)$ & \\
\hline Science and technology make our lives easier & $4.25(0.77)$ & \\
\hline $\begin{array}{l}\text { Science and technology can play a role in improving } \\
\text { the environment }\end{array}$ & $4.56(0.61)$ & \\
\hline I have confidence in the reliability of science ${ }^{\mathrm{a}}$ & $3.9(0.9)$ & \\
\hline Trust in science & $3.62(0.85)$ & .51 \\
\hline I have confidence in the reliability of science ${ }^{a}$ & $3.90(0.87)$ & \\
\hline $\begin{array}{l}\text { I expect scientists to manipulate their results and } \\
\text { conclusions to get the results they want (reverse coded) }\end{array}$ & $3.34(1.18)$ & \\
\hline \multicolumn{3}{|l|}{ Not loaded onto scale } \\
\hline I donate to scientific or medical research & $3.26(1.4 I)$ & \\
\hline
\end{tabular}

SD: standard deviation.

$N=|| 23$.

aOne item loaded onto two scales.

interest as motivation scale $\left(r_{s}=.28\right)$. Not surprisingly, people who engaged more in scientific activities in their daily lives were more inclined to join the iSPEX project because they were interested in science or because they thought of iSPEX as a fun experience (although for the entire sample, fun was not the most important reason to join).

\section{Expectations about the project}

When asked about what they thought the findings of iSPEX could accomplish, many respondents had high expectations. Respondents thought that the combined iSPEX measurements will give a good representation of aerosols in the Netherlands $(M=4.35, S D=0.68)$, that scientists will not present an overly positive picture of the data (reversely coded, $M=4.00, S D=0.93$ ), that data can be used to impact environmental policy $(M=4.04, S D=0.90)$ and that the data can be used to impact health policy $(M=4.01, S D=0.88)$.

Comparing respondents' motivation to participate and their expectations about the impact of the project revealed several significant correlations (see Table 3). Most importantly, people who participated in the project because they wanted to contribute to science, health or the environment tended to have higher expectations about the impact the iSPEX results could have on health and environmental policy $\left(r_{s}=.29, r_{s}=.26\right.$, respectively; $\left.p \mathrm{~s}<.01\right)$. In addition, a significant correlation existed between the expectation of the impact on health policy and health concern as a motivator $\left(r_{s}=.29 ; p<.01\right)$. 
Table 2. Motivation to contribute to iSPEX.

\begin{tabular}{|c|c|c|}
\hline Scale and items & Mean $(S D)$ & Reliability $(\alpha)$ \\
\hline Contribution & $4.41(0.66)$ & .85 \\
\hline Contribute to general health & $4.41(0.85)$ & \\
\hline Help improve the environment & $4.40(0.86)$ & \\
\hline Contribute to quality of surroundings & $4.43(0.86)$ & \\
\hline Contribute to scientific research ${ }^{a}$ & $4.66(0.68)$ & \\
\hline Important to get as much measurements as possible & $4.43(0.86)$ & \\
\hline Government should do more about air qualitya & $4.11(1.08)$ & \\
\hline Interest in science & $4.11(0.63)$ & .75 \\
\hline Interested in science and technology & $4.26(0.94)$ & \\
\hline Learn about science & $3.80(1.05)$ & \\
\hline Fun activity ${ }^{a}$ & $4.14(1.00)$ & \\
\hline Citizen science is interesting method & $4.22(0.95)$ & \\
\hline Contribute to scientific research ${ }^{a}$ & $4.66(0.68)$ & \\
\hline Interested in aerosols ${ }^{\mathrm{a}}$ & $3.57(1.05)$ & \\
\hline Concern for health & $3.44(0.83)$ & .72 \\
\hline Knowing where and when to expect impact on my own health & $3.44(1.30)$ & \\
\hline Measuring air quality at my location & $4.07(1.09)$ & \\
\hline Government should do more about air qualitya & $4.11(1.08)$ & \\
\hline Interested in aerosols $\mathrm{s}^{\mathrm{a}}$ & $3.57(1.05)$ & \\
\hline I have asthma/shortness of breath & $2.01(1.47)$ & \\
\hline Fun & $2.99(0.84)$ & .67 \\
\hline Being involved through Internet and social media & $3.00(1.34)$ & \\
\hline Meeting people with similar interests & $2.23(1.08)$ & \\
\hline Fun gadget & $2.58(1.30)$ & \\
\hline Fun activity ${ }^{a}$ & $4.14(1.00)$ & \\
\hline Use in schools & $1.50(0.79)$ & .70 \\
\hline Use iSPEX for teaching & $1.68(1.04)$ & \\
\hline Required for school/study & $1.31(0.74)$ & \\
\hline
\end{tabular}

SD: standard deviation.

$N=|| 23$.

aThese items load on more than one component.

\section{Conditions for future participation}

Promisingly, $42.3 \%$ of respondents indicated they want to take measurements as often as needed. In addition, 28\% want to take measurements a couple of times a year. Only six respondents indicated they do not want to contribute to iSPEX anymore. The majority of people want to take measurements by themselves, but want to either be reminded to do so (42\%) or they want to collect data at a designated measurement day (38\%). In order to remind people of measurement days or to update them about the project, most people prefer to be contacted through email (85\%) or through the app (60\%). Moreover, respondents would like to get more information about what happens with their individual data $(87 \%)$, about how the add-on works $(52 \%)$ and about how the application works $(44.5 \%)$.

\section{Learning impact}

Respondents were asked to score on a 5 -point Likert scale $(1=$ not at all applicable, $5=$ totally applicable) if they had learned something about a list of topics as a result of the iSPEX project 
Table 3. Correlations between motivation versus age, attitude and expectations.

\begin{tabular}{|c|c|c|c|c|c|}
\hline & \multicolumn{5}{|c|}{ Motivation scale } \\
\hline & Contribution & Interest & Health concern & Fun & School \\
\hline Age & $.23 * * *$ & $.13 * * *$ & $.15^{* * *}$ & $.15 * * *$ & .02 \\
\hline \multicolumn{6}{|l|}{ Attitude scale } \\
\hline Activities & $.10 * *$ & $.40 * * *$ & .01 & $.25 * * *$ & $.19 * * *$ \\
\hline Optimism & $.17^{* * *}$ & $.28^{* * *}$ & .06 & $.14 * * *$ & -.01 \\
\hline Trust & .03 & $.10^{* *}$ & .02 & .05 & -.03 \\
\hline \multicolumn{6}{|l|}{ Expectations } \\
\hline Good representation & $.21^{* *}$ & $.18^{* *}$ & $.19 * *$ & $.12^{* *}$ & .02 \\
\hline Not overly positive & $.16 *$ & $.12^{* *}$ & $.07^{*}$ & .02 & $.11 * *$ \\
\hline Impact on environmental policy & $.26 * *$ & $.10^{* *}$ & $.21^{* *}$ & $.11 * *$ & .00 \\
\hline Impact on health policy & $.29 * *$ & $.10 * *$ & $.29 * *$ & $.08 * *$ & .04 \\
\hline
\end{tabular}

$N=$ I I23; Grey $=$ effect size $r>.25$.

$* p<.05 ; * * p<.01 ; * * * p<.001$.

(reliability coefficient of $\alpha=.78$ ). The item about learning about how citizens can contribute to scientific research was most applicable $(M=4.28, S D=0.90)$, followed by learning about aerosols $(M=3.70, S D=1.10)$, about the physical concepts underlying iSPEX (e.g. polarisation; $M=3.61$, $S D=1.14)$, about the health effects of aerosols $(M=3.48, S D=1.15)$ and about the climate effects of aerosols $(M=3.23, S D=1.14)$. Respondents were less inclined to agree that they had learned something about the workings of their smartphones $(M=2.64, S D=1.24)$. A scale score was calculated for each of the respondents to use in further analysis by taking the average of the items of the learning impact scale $(M=3.49, S D=0.77)$.

A significant positive correlation was found between age and self-reported impact on learning $\left(r_{s}=.17, p<.001\right)$, meaning that older people tended to report more often that they had learned something from the iSPEX project. A one-way analysis of variance (ANOVA) was conducted to determine whether there were differences across education levels on the learning impact. A small but significant effect was found, $F(4,1111)=8.64, p<.001, \omega^{2}=.03$. Post hoc analysis (Tukey) revealed that people who had finished high school $(M=3.65, S D=0.80, n=108)$, community college ('MBO'; $M=3.70, S D=0.71, n=99$ ) or a 4-year professional bachelor ('HBO'; $M=3.55$, $S D=0.75, n=363$ ) were more inclined to report an impact on learning than people with a university degree $(M=3.38, S D=0.76, n=535)$ or people with an elementary education or less $(M=2.64$, $S D=1.22, n=7)$.

\section{Understanding of the project}

In order to examine how well respondents understood how the iSPEX measurements work, respondents were asked to mark six statements about the project as either true or false. All of these statements were about topics that were on the project website and have been explained in the communication to the respondents several times. The average total score was 2.7 out of six questions ( $45 \%$ correct; see Table 4). Statements about the importance of averaging over several measurements were answered correctly (AVERAGE, 84\% correct; and ONE_MEASUREMENT, 73\% correct). Questions that related to the complex technology behind the measurements were harder for these respondents. For example, many people thought the iSPEX measurements give information 
Table 4. Understanding of the iSPEX project.

Statement (true/false)

Correct answer (\%)

The average of all measurements in my region gives a good measure of

84

the amount of aerosols in the atmosphere in my region (AVERAGE; true).

One measurement of iSPEX is not a reliable measure of the air quality

(ONE_MEASUREMENT; true).

The iSPEX app measures aerosols close to the ground as well as higher up in the atmosphere (COLUMN; true).

iSPEX measurements can be used to determine whether existing aerosol norms (PMI0, PM2.5) are not exceeded (NORMS; false).

The colour code in the app gives a good measure of the amount of aerosols in the air at my location (COLOR_CODE; false).

iSPEX measurements give an indication of the exposure of people to aerosols at my location (EXPOSURE; false).

Average over all six questions.

73

41

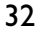

30

II

45

$N=|| 23$.

about the exposure of people at their location (EXPOSURE, 11\% correct). This is considered incorrect because the aerosol load as measured by iSPEX can be at high altitude instead of ground level. In addition, the colour code in the app does not give a direct measure of the amount of aerosols at that location (COLOUR CODE, 30\% correct) due to large systematic errors.

A small but significant correlation was found between understanding of the project and the expectations of what iSPEX can achieve in terms of impact on policy. The more understanding respondents showed of what the project could and could not measure, the lower their expectations about the quality of the iSPEX data $\left(r_{s}=-.14, p<.001\right)$, about the impact of the project on health policy $\left(r_{s}=-.12, p<.001\right)$ and about the impact on environmental policy $\left(r_{s}=-.09, p<.001\right)$.

\section{Discussion}

It is important to gain understanding of what motivates participants to become part of CS projects and what they can learn from these projects. We found that the most important reason for people to join the Dutch iSPEX project was contribution to scientific research, the environment and health. Respondents were motivated to stay involved after the initial stages of the project, but would like to be kept up to date about what happens with their data. Respondents self-reported that they had learned something about CS and the specific topics of the project (i.e. aerosols). Interestingly, understanding of the science behind the iSPEX measurements, measured through true/false questions, was rather low, indicating that many respondents did not have a correct understanding of how the iSPEX measurements work.

\section{Citizen scientists}

On average, iSPEX participants were middle-aged men with a higher education degree and a fulltime job. Although demographic data are not consistently collected in all CS projects, many CS participant studies report groups of participants who are well-educated (Brossard et al., 2005; Cooper et al., 2010; Crall et al., 2012; Evans et al., 2005; Jordan et al., 2011; Price and Lee, 2013; Thompson and Bonney, 2007; Trumbull et al., 2000) and mostly middle-aged (Crall et al., 2012; Jordan et al., 2011; Thompson and Bonney, 2007; Trumbull et al., 2000). Despite the 
high education level of participants, the iSPEX project was able to engage an audience with little previous experience with science in general and CS in particular. This finding suggests that this type of CS can be used to connect people with science. Future research is needed to determine whether, after this initial encounter, people stay involved or interested in science.

\section{Motivations}

The most important reasons for respondents to join iSPEX were because they wanted to contribute to scientific research, the environment or health and because they were interested in science and the topics of the project (aerosols and the impact on health and environment). These findings show a similar pattern to many other CS projects where contribution to the project goals and an interest in the project topics are the most important motivational factors (Dickinson et al., 2012; Newman et al., 2012; Roy et al., 2012). However, where Rotman et al. (2012) found that egoism (one's own good) was the most important motive during initial participation, we found that people had a more altruistic or collectivistic motivation, even at the start of their participation. Reasons relating to altruism such as contributing to scientific research and reasons related to collectivism such as contributing to general health or contributing to general surroundings scored higher than reasons relating to egoism such as one's own interest, a fun activity or learning. It is not easy to pinpoint the cause of this difference. Possibly, the way the project was described and promoted as a way to be part of a scientific project or to contribute to general health and environment (as described above) triggered altruistic and collectivistic motives. Rotman et al. (2012) underline the relationship between participants' motivation and the way the project is attuned to those motivations. This suggests that motivation not only changes over time but is also influenced by the type of project and the way the organisers communicate the project's goals and importance.

Some of the other findings of this study support this suggestion. People who engage more in science activities in their daily lives tended to join iSPEX out of an interest in science. Also, people who had higher expectations about the impact the iSPEX results could have on environmental and health policy tended to join iSPEX because they wanted to contribute to science and health or because they were concerned about their own health. Both the interest in science and a drive to impact policy may be important ways to frame CS projects.

Although the iSPEX project is a rather young project, we found that most respondents want to stay involved with the project. One of the important prerequisites is that participants want to get feedback about their contributions and their data. This finding resonates with many other studies where feedback is an important factor in prolonged engagement with CS (Chu et al., 2012; Devictor et al., 2010; Sullivan et al., 2009). The challenge for the iSPEX project is the amount of analysis that is needed to translate raw data (existing of several pictures per measurement) into aggregate maps of aerosol characteristics. In the future, once analysis of the data has been automated, feedback will be available for participants on a much quicker timescale.

These findings about motivation imply that once again, contribution to a larger effort (scientific, health related or environmental) is an important motivational factor for the public to start participating in a CS project. Gearing communication and design of CS projects towards these types of motives will aid in attracting and retaining participants (Chu et al., 2012; Rotman et al., 2012).

\section{Learning impact}

Through their participation in the iSPEX project, respondents self-reported to have learned about how citizens can contribute to scientific research. This finding matches the fact that for many respondents, this was the first time they joined a CS project. Respondents also somewhat agreed to having learned about aerosols and their health and environmental impact, the specific topics of the 
iSPEX project. On average, self-reported learning impact was not particularly high. Furthermore, respondents scored rather low on understanding of the iSPEX project. Most importantly, people seem to expect immediate feedback on the aerosol load at ground level. However, iSPEX measurements are indirect, remote-sensing measurements (as explained in the introduction), which means data that are being collected by the add-ons and smartphones can only be translated into detailed aerosol properties after extensive analyses which take time. Possibly, people are used to instruments taking direct measurements such as a thermometer measuring temperature at that location or even an aerosol cassette that does measure aerosol concentration at the same location.

Implications of these findings about learning impact and understanding of the project are that organisers of the iSPEX project and other projects need to find ways to help participants gain a better understanding of the science behind the measurements, especially when the science is rather complex. Although for respondents of this study learning more about science was not an important motive, some CS organisers may prefer that participants have some understanding of the underlying science of the project and of the associated measurements. Future research should investigate strategies to help participants understand the project. Other studies showed that explicit training of participants can increase the science learning impact. Cronje et al. (2011) showed that contextual knowledge in particular, that is, knowledge about the specific topics of the project, can be impacted by participation in a CS project. However, there is a trade-off between involving as many participants as possible (several thousand for this project) and training each and every one of them.

\section{Social aspect}

Another interesting set of findings from this study are those about the social aspect of the iSPEX project. Although the social aspect of CS is relevant for certain CS projects (Dickinson et al., 2012; Jennett et al., 2013; Reed et al., 2013), in this study, respondents did not seem to be interested in forming a community or interacting with other participants. Respondents did not take measurements together with others, and meeting people with similar interest and becoming involved through Internet and social media scored low as motivational factors. Other examples exist of projects where social involvement is less important to participants. For example, Nov et al. (2011a) reported only a small role for social interaction as motivating factor for participation in the Stardust@Home project (where citizen scientists look for interstellar dust particles on images of gel collectors). In addition, even for Galaxy Zoo, a project with an active forum for participants, becoming part of a community was the least important reason for participation (Raddick et al., 2013). Contribution to both of these projects happens online, possibly attracting people who would like to contribute to scientific research in their own time and fitting their own schedule. Similarly, taking an iSPEX measurement is something you can easily do by yourself in your own time. Interestingly, however, many iSPEX participants did explain to others what they were doing during their measurements.

\section{Conclusion}

In conclusion, as an example of a rather new type of CS that uses smartphones with an add-on as actual measurement devices, the iSPEX project attracted a new audience for (citizen) science. Participants were primarily motivated by a willingness to contribute to a larger effort - scientific, environmental or health. These motivations match the project's goal to engage people in the scientific process and to use data on aerosols to improve scientific knowledge about environment and health. Participants prefer to take individual measurements that take a limited amount of time and are not interested in becoming part of a community or interacting with other citizen scientists. They do want to stay up to date with the project and receive feedback about the results of the CS studies. 
Therefore, communication and project organisation of this and similar projects should be framed in a way that matches participants' motivations (Chu et al., 2012; Rotman et al., 2012). We suggest that similar projects based on complex science find ways to make sure participants (who may invest only a small amount of time) receive information about the underlying science and have some understanding of what their measurements actually mean. However, in the iSPEX project, a less than perfect understanding of the project did not keep people from being able to perform the measurements and enjoy their participation in the project.

\section{Funding}

Anne M. Land-Zandstra conducted the participant study and was not funded for her research. Jeroen L. A. Devilee, Frans Snik, and Franka Buurmeijer were part of the project's consortium which was funded partly by the "Academische Jaarprijs 2012". Jos M. van den Broek was not funded for his contribution to the manuscript.

\section{Notes}

1. http://www.opalexplorenature.org

2. http://www.natuurkalender.nl

3. http://www.zooniverse.org

4. http://www.noisetube.net

5. http://www.ibats.org.uk

6. http://www.ispex.nl

7. This citizen science project was made possible by the Academische Jaarprijs 2012 , a $€ 100,000$ prize for translating scientific research to the general public, awarded to the iSPEX team (Leiden University, the Dutch Research School for Astronomy NOVA, The Netherlands Institute for Space Research SRON, the Royal Netherlands Meteorological Institute KNMI, and the National Institute for Public Health and the Environment RIVM). The iSPEX team collaborates with the following partners: Longfonds (Lung Foundation), CNG Net, Sanoma and Avantes.

\section{References}

Batson CD, Ahmad N and Tsang JA (2002) Four motives for community involvement. Journal of Social Issues 58(3): 429-445.

Bonney R, Ballard H, Jordan R, McCallie E, Phillips T, Shirk J, et al. (2009a) Public participation in scientific research: Defining the field and assessing its potential for informal science education. A CAISE Inquiry Group Report, Center for Advancement of Informal Science Education (CAISE), Washington, DC, July.

Bonney R, Cooper CB, Dickinson J, Kelling S, Phillips T, Rosenberg KV, et al. (2009b) Citizen science: A developing tool for expanding science knowledge and scientific literacy. BioScience 59(11): 977-984.

Brossard D, Lewenstein B and Bonney R (2005) Scientific knowledge and attitude change: The impact of a citizen science project. International Journal of Science Education 27(9): 1099-1121.

Catlin-Groves CL (2012) The citizen science landscape: From volunteers to citizen sensors and beyond. International Journal of Zoology 2012: 1-14.

Chu M, Leonard P and Stevenson F (2012) Growing the base for citizen science: Recruiting and engaging participants. In: Dickinson JL and Bonney R (eds) Citizen Science: Public Participation in Environmental Research. Ithaca, NY: Cornell University Press, pp. 69-81.

Cook C, Heath F and Thompson RL (2000) A meta-analysis of response rates in web- or internet-based surveys. Educational and Psychological Measurement 60(6): 821-836.

Cooper S, Khatib F, Treuille A, Barbero J, Lee J, Beenen M, et al. (2010) Predicting protein structures with a multiplayer online game. Nature 466: 756-760.

Crall AW, Jordan R, Holfelder K, Newman GJ, Graham J and Waller DM (2012) The impacts of an invasive species citizen science training program on participant attitudes, behavior, and science literacy. Public Understanding of Science 22(6): 745-764. 
Cronje R, Rohlinger S, Crall A and Newman G (2011) Does participation in citizen science improve scientific literacy? A study to compare assessment methods. Applied Environmental Education and Communication 10(3): 135-145.

Devictor V, Whittaker RJ and Beltrame C (2010) Beyond scarcity: Citizen science programmes as useful tools for conservation biogeography. Diversity and Distributions 16(3): 354-362.

Dickinson JL, Shirk J, Bonter D, Bonney R, Crain RL, Martin J, et al. (2012) The current state of citizen science as a tool for ecological research and public engagement. Frontiers in Ecology and the Environment 10(6): 291-297.

Druschke CG and Seltzer CE (2012) Failures of engagement: Lessons learned from a citizen science pilot study. Applied Environmental Education and Communication 11(3-4): 178-188.

Evans C, Abrams E, Reitsma R, Roux K, Salmonsen L and Marra PP (2005) The Neighborhood Nestwatch program: Participant outcomes of a citizen-science ecological research project. Conservation Biology 19(3): 589-594.

Haklay M (2012) Citizen science and volunteered geographic information: Overview and typology of participation. In: Sui DZ, Elwood S and Goodchild MF (eds) Crowdsourcing Geographic Knowledge: Volunteered Geographic Information (VGI) in Theory and Practice. Berlin: Springer, pp. 105-122.

Jennett C, Furniss DJ, Iacovides I, Wiseman S, Gould SJJ and Cox AL (2014) Exploring citizen psychscience and the motivations of Errordiary volunteers. Human Computation 1(2): 199-218.

Jennett C, Kloetzer L, Gold M and Cox AL (2013) Sociability in virtual citizen science. In: Proceedings of the CHI 2013 workshop on designing and evaluating sociability in online video games, Paris, 27 April, New York, NY: ACM, pp. 29-32.

Jordan RC, Gray SA, Howe DV, Brooks WR and Ehrenfeld JG (2011) Knowledge gain and behavioral change in citizen-science programs. Conservation Biology 25(6): 1148-1154.

Lee S and Roth W (2003) Science and the 'good citizen': Community-based scientific literacy. Science, Technology \& Human Values 28(3): 403-424.

Mueller M, Tippins D and Bryan L (2012) The future of citizen science. Democracy \& Education 20(1): 1-12.

National Research Council (2009) Learning Science in Informal Environments: People, Places, and Pursuits. Washington, DC: National Academies Press.

Newman G, Wiggins A, Crall A, Graham E, Newman S and Crowston K (2012) The future of citizen science: Emerging technologies and shifting paradigms. Frontiers in Ecology and the Environment 10(6): 298-304.

Nov O, Arazy O and Anderson D (2011a) Dusting for science: Motivation and participation of digital citizen science volunteers. In: Proceedings of the 2011 iConference, Seattle, WA, 8-11 February, pp. 68-74. New York, NY: ACM.

Nov O, Arazy O and Anderson D (2011b) Technology-mediated citizen science participation: A motivational model. In: Proceedings of the AAAI international conference on weblogs and social media, Barcelona, Spain, 17-21 July, pp. 249-256. Menlo Park, CA: The AAAI Press.

Price CA and Lee H-S (2013) Changes in participants' scientific attitudes and epistemological beliefs during an astronomical citizen science project. Journal of Research in Science Teaching 50(7): 773-801.

Raddick MJ, Bracey G, Gay PL, Lintott CJ, Cardamone C, Murray P, et al. (2013) Galaxy Zoo: Motivations of citizen scientists. Astronomy Education Review, 12(1). DOI: 10.3847/AER2011021.

Raddick MJ, Bracey G, Gay PL, Lintott CJ, Murray P, Szalay AS, et al. (2010) Galaxy Zoo: Exploring the motivations of citizen science volunteers. Astronomy Education Review 9(1). DOI: 10.3847/AER2009036

Reed J, Raddick MJ, Lardner A and Carney K (2013) An exploratory factor analysis of motivations for participating in Zooniverse, a collection of virtual citizen science projects. In: Proceedings of the 46th Hawaii international conference on system sciences, Wailea, HI, 7-10 January, pp. 610-619. Washington, DC: IEEE Computer Society.

Riesch H and Potter C (2014) Citizen science as seen by scientists: Methodological, epistemological and ethical dimensions. Public Understanding of Science 23(1): 107-120.

Riesch H, Potter C and Davies L (2013) Combining citizen science and public engagement: The Open Air Laboratories Programme. Journal of Science Communication, 12(3). Available at: http://jcom.sissa.it/ sites/default/files/documents/JCOM1203(2013)A03.pdf

Rotman D, Preece J, Hammock J, Procita K, Hansen D, Lewis D, et al. (2012) Dynamic changes in motivation in collaborative citizen-science projects. In: Proceedings of the ACM conference on computer supported cooperative work, Seattle, WA, 11-15 February, pp. 217-226. New York, NY: ACM. 
Roy HE, Pocock MJO, Preston CD, Roy DB, Savage J, Tweddle JC, et al. (2012) Understanding citizen science and environmental monitoring. Final Report on behalf of UK-EOF, NERC Centre for Ecology \& Hydrology and Natural History Museum. Wallingford, Oxfordshire, UK: Centre for Ecology \& Hydrology.

Sauermann H and Franzoni C (2015) Crowd science user contribution patterns and their implications. Proceedings of the National Academy of Sciences 112: 679-684.

Science Communication Unit, University of the West of England-Bristol (2013) Science for environmental policy in-depth report: Environmental citizen science. Report produced for the European Commission DG Environment, December. Bristol, UK.

Silvertown J (2009) A new dawn for citizen science. Trends in Ecology \& Evolution 24(9): 467-471.

Snik F, Rietjens JHH, Apituley A, Volten H, Mijling B, Di Noia A, et al. (2014) Mapping atmospheric aerosols with a citizen science network of smartphone spectropolarimeters. Geophysical Research Letters 41(20): 7351-7358.

Socientize (2013) Citizen Science for Europe: Towards a Better Society of Empowered Citizens and Enhanced Research (Green paper on citizen science). The Socientize consortium. Available at: www.socientize.eu

Sullivan BL, Wood CL, Iliff MJ, Bonney RE, Fink D and Kelling S (2009) eBird: A citizen-based bird observation network in the biological sciences. Biological Conservation 142(10): 2282-2292.

Theobald EJ, Ettinger AK, Burgess HK, DeBey LB, Schmidt NR, Froehlich H, et al. (2015) Global change and local solutions: Tapping the unrealized potential of citizen science for biodiversity research. Biological Conservation 181: 236-244.

Thompson S and Bonney R (2007) Evaluating the impact of participation in an online citizen science project: A mixed-methods approach. In: Trant J and Bearman D (eds) Museums and the Web 2007: Proceedings. Toronto, ON, Canada: Archives \& Museum Informatics. Available at: http://www.archimuse.com/ mw2007/papers/thompson/thompson.html

Trumbull DJ, Bonney R, Bascom D and Cabral A (2000) Thinking scientifically during participation in a citizen-science project. Science Education 84(2): 265-275.

Wiggins A and Crowston K (2012) Describing public participation in scientific research. In: Proceedings of the 2012 iConference, Toronto, ON, Canada, 7-10 February. New York, NY: ACM.

Wymer WW (2003) Differentiating literacy volunteers: A segmentation analysis for target marketing. International Journal of Nonprofit and Voluntary Sector Marketing 8(3): 267-285.

\section{Author biographies}

Anne M. Land-Zandstra, PhD, is a Postdoctoral Researcher and Lecturer in the field of informal science education at the Science Communication and Society Department at Leiden University in the Netherlands. Her research interests are participant outcomes of citizen science projects and informal science education in museums.

Jeroen L. A. Devilee, PhD, is Researcher in the field of risk and society at the National Institute for Public Health and the Environment (RIVM) since 2007. He works on projects that include the way that citizens, scientists, policy makers and society at large respond to risks and (new) technological developments.

Frans Snik, PhD, works as an Astronomer at Leiden University, where he develops innovative instrumentation for astronomical and atmospheric research. He invented a novel polarimetric method for measuring atmospheric particles, which led to the SPEX (satellite) instrument concept. He leads the iSPEX project that involves thousands of citizen scientists and their smartphones to perform crowdsourced measurements of air pollution.

Franka Buurmeijer, MSc, is an Astronomer and Science Communicator with a strong interest in the communication of the physical sciences and mathematics, and gender inequalities in these fields. She is currently the outreach coordinator at the Anton Pannekoek Institute for Astronomy in Amsterdam and project officer at VHTO, the national organisation of girls/women in science/technology.

Jos M. van den Broek, PhD, was a Science Writer and Editor for over 20 years. He authored several popular science books and is the first author of the textbook Visual Language (Eleven Publishers, 2012). As a professor in science communication, he now heads the Science Communication and Society Department of Leiden University. His main interests are visual language and health communication. 